\title{
Children computer mouse use and anthropometry
}

\author{
Erin E. Hughes ${ }^{\mathrm{a}}$, and Peter W. Johnson ${ }^{\mathrm{a}}$ \\ ${ }^{a}$ Department of Environmental and Occupational Health Sciences, University of Washington, 4425 Roosevelt Way \\ NE, Suite 100, Seattle, WA, USA
}

\begin{abstract}
Studies have shown that increased computer use among adults in occupational settings is associated with the development of cumulative trauma disorders; however, the need to address how adult-sized mice and keyboards are affecting children is becoming increasingly important as both access to and use of computers is increasing among today's youth. To address the potential mismatch that exists between child stature and computer input device size and activation force, we have applied existing, age-specific, anthropometric data to elements of device design, including mouse size (length, width, height, switch location), and mouse-button activation forces. Trends supported the development of smaller computer input devices with lower activation forces for smaller statured individuals including children. Distinct and consistent trends in size delineations were seen across gender and age groups - trends that correlate well with grades and schooling in the United States education system Three to four mouse sizes would be recommended: a mouse sized for adult and high school males; one for adult and high school females and junior high males; one for elementary school children, aged 6 to 10 years; and possibly a mouse for the smallest users who are less than six years old.
\end{abstract}

Keywords: design, mouse, keyboard, stature, standards

\section{Introduction}

Computer use has increased dramatically both among adult and youth populations. There is a substantial amount of literature on ergonomic considerations for adult computer use, showing that increased use in occupational settings are associated with the development of cumulative trauma disorders or other soft tissue problems in the neck and shoulders, forearm, wrist, and hand [14,17], and that adult women may be at greater risk $[3,18]$. However, there is a lack of objective data on how the current adult sized design paradigm for computer input devices may affect smaller statured users (adult women) and children [1,12].

Although children are not using computers with the same frequency or sustained intensity as adults in occupational settings do [4], a few pioneering studies have linked computer use to musculoskeletal discomfort among children $[9,11,13,16]$. With both access to and use of computers on the rise among youth, the need address how computer input device design is affecting children is becoming increasingly important $[7,15]$.

Considering the design implications of the mouse is important because mouse use may account for $30-80 \%$ of the time working at the computer [8]. In a study comparing mouse use between healthy children, ages 5-8 years, and their same gender biological parent, Blackstone et al [2] found that children worked with 18.2 degrees more ulnar deviation when compared to the adults when using a standard "adult-sized" mouse. However, when the same groups of subjects used a 33\% smaller, more child proportional mouse, children's' wrist posture improved. Non-neutral postures are implicated in the development of musculoskeletal disorders.

Another study [6] measured wrist posture, performance, and preferences of both children and adults while they used three different sized mice (standard, medium and small). Cui [6] found that size of mouse did not significantly affect wrist posture among adults, but that children's wrist posture was significantly reduced using the medium and small mice. Small and medium mice also improved child 
performance and decreased muscle activity in wrist extensor and finger muscles, while not creating any adverse effect on the performance or muscle activity of adults.

These studies support making different sizes of computer input devices to account for the different statures of adults and children. Using pertinent anthropometric data, the purpose of this study is to address the increasingly relevant concerns of the mismatch between the design of computer input devices and the smaller statured women and children that use them. By applying the relevant anthropometric data from adult males, adult females and children to the design of computer input devices, we hope to develop recommendations which may lead to new standards for adult gender-specific and child-specific computer input device designs. Included in this report are quantitative guidelines for mouse size and mouse button activation force.

\section{Methods}

Anthropometry is the systematic measurement of body dimensions, and can be a useful tool when trying to determine the proper sizes and activation forces of computer input devices. The optimal size and shape of a computer input device, such as the mouse, is likely the size that fits comfortably and is proportional with one's stature. For example, the arc length of a mouse and the width of a mouse could be designed based on the length and width of the user's hand. The location of the mouse button switch could be determined using data on index finger length.

Using existing anthropometric databases, normal distribution curves were created based on the means and standard deviations of existing, age-specific, child and adult anthropometric data from US populations. The data were then analyzed to determine between which age groups the natural size delineations exist. As shown in Figure 1, starting from the adult male, a size delineation was created when the mean from one age or gender group fell outside the 5th95th percentile range of an adjacent group. Thus an age or gender group was considered similar enough to the adjacent group when the majority of their population fell within the 5th-95th percentile range of that group.

Using the above described size delineation process, adult males were used as the base group then compared to adult females. If females were not a separate population, this process continued sequentially going through the child anthropometric data starting with 13 year olds. The analysis excluded data from 14-18 year olds since the anthropometric data indicated this group approximated their adult, samegender counterparts. These delineations were used to derive age- and gender-specific recommendations by which computer input devices could be designed to create stature proportional computer input devices.

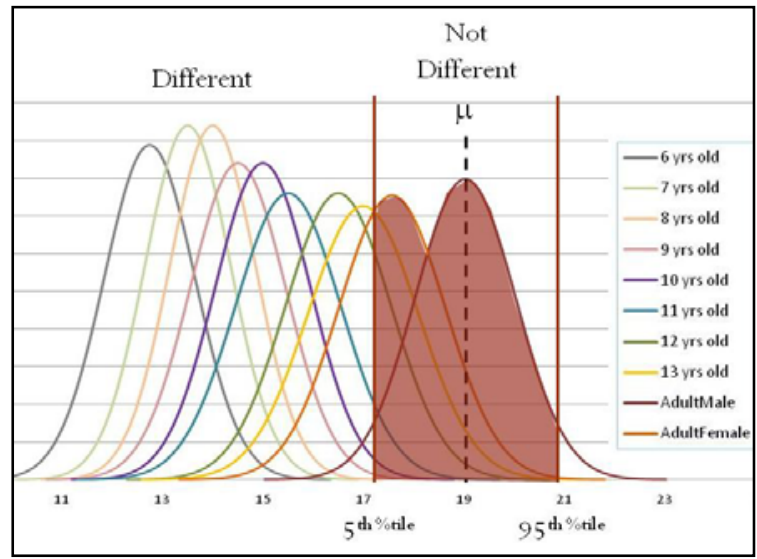

Fig 1: Statistical method for size delineations

The ANSI and ISO standards provide recommendations for computer input device activation forces. The current recommended mouse-button activation forces range between $0.5 \mathrm{~N}$ to $1.5 \mathrm{~N}$. For determining a range of acceptable mouse button activation forces for children and adults, finger mass was used to derive mouse button activation forces. Using the method previously validated by Hwang and Johnson [10], finger mass was calculated taking the volume of the index finger and multiplying it by the density of human tissue $\left(1.16 \mathrm{~g} / \mathrm{cm}^{3}\right)$ [5].

It appears most input device activation forces are roughly twice the mass of the 50th percentile male's finger. The appropriate mouse-button activation force was determined by multiplying finger mass by a factor of two. A multiplier of two has been recommended as a safety factor for operations requiring manipulation with the finger [19], and seemed justifiable based on the factor of two anthropometric scaling. 


\section{Results}

\subsection{Size}

\section{Device length}

The working assumption for mouse length, based on the length of standard commercially available mice, was that the $12.0 \mathrm{~cm}$ long mouse was based on accommodating the size of the 50th percentile males' hand. This yields a proportion where mouse length should be $63 \%$ of hand length. Natural size delineations in the hand length data yielded four age groups: adult males and females; and children ages 10-13; 59; and 3-4 years. As indicated in Table 1, in addition to the standard $12 \mathrm{~cm}$ mouse, three addition mouse lengths of $10.0 \mathrm{~cm}, 8.5 \mathrm{~cm}$, and $7.2 \mathrm{~cm}$ would be recommended.

\section{Device width}

The working assumption for mouse width, based on the width of standard commercially available mice, was that the $6.2 \mathrm{~cm}$ wide mouse was based on accommodating the size of the 50th percentile males' hand. This yields a proportion where mouse width should be $71 \%$ of hand width. As indicated in Table 1 , the natural size delineations in hand width data yielded four age groups: adult males, adult females which included children ages 10-13; and children ages 5-9; and 3-4.

\section{Device height}

The working assumption for mouse height, based on the height of standard commercially available mice being $3.8 \mathrm{~cm}$ tall, was that mouse height should be $78 \%$ of the of the thickness of the 50 th percentile males' wrist. Wrist depth data was not available for adults; however, wrist breadth and circumference data was available for both children and adults. Using the average wrist circumference to wrist depth ratio for children by age group, and applying this ratio to adult male and female circumference values, values for adult wrist depth by gender were estimated. This ratio was fairly consistent across ages 3-13, supporting the assumption that proportionality would be conserved in adults as well.

Natural size delineations in the wrist depth data yielded three age groups: adult males and females; and children ages 9-13; and 3-5. As shown in Table 1 , additional mice heights of $2.6 \mathrm{~cm}$ and $2.3 \mathrm{~cm}$ would be recommended.
Table 1: Recommended mouse (RM) length, width and height based on hand and wrist anthropometric dimensions

\begin{tabular}{|c|c|c|c|c|c|c|}
\hline Age & $\begin{array}{l}\text { Hand } \\
\text { length } \\
(\mathrm{cm})\end{array}$ & $\begin{array}{c}\text { RM } \\
\text { length } \\
(\mathrm{cm})\end{array}$ & $\begin{array}{c}\text { Hand } \\
\text { W } \\
(\mathrm{cm})\end{array}$ & $\begin{array}{c}\text { RM } \\
\text { width } \\
(\mathrm{cm})\end{array}$ & $\begin{array}{l}\text { Wrist } \\
\text { depth } \\
(\mathrm{cm})\end{array}$ & $\begin{array}{c}\text { RM } \\
\text { height } \\
(\mathrm{cm})\end{array}$ \\
\hline$\hat{0}$ & 19.0 & $\begin{array}{c}12 \\
\text { (grp1) }\end{array}$ & 8.7 & $\begin{array}{c}6.2 \\
\text { (grp1) }\end{array}$ & 4.9 & $\begin{array}{c}3.8 \\
\text { (grp1) }\end{array}$ \\
\hline 우 & 17.6 & & 7.8 & \multirow{5}{*}{$\begin{array}{c}5.2 \\
(\operatorname{grp} 2)\end{array}$} & 4.4 & \\
\hline 13 & 17.0 & \multirow{4}{*}{$\begin{array}{c}10.0 \\
\text { (grp2) }\end{array}$} & 7.8 & & 3.7 & \multirow{6}{*}{$\begin{array}{c}2.6 \\
\text { (grp2) }\end{array}$} \\
\hline 12 & 16.5 & & 7.2 & & 3.6 & \\
\hline 11 & 15.5 & & 7.0 & & 3.4 & \\
\hline 10 & 15.0 & & 7.0 & & 3.4 & \\
\hline 9 & 14.5 & \multirow[b]{2}{*}{8.5} & 6.5 & \multirow[b]{2}{*}{4.4} & 3.3 & \\
\hline 8 & 14.0 & & 6.5 & & 3.3 & \\
\hline 7 & 13.5 & \multirow[t]{3}{*}{ (grp3) } & 6.2 & \multirow[t]{3}{*}{ (grp3) } & 3.2 & \\
\hline 6 & 12.8 & & 6.0 & & 3.1 & \\
\hline 5 & 12.6 & & 5.8 & & 3.0 & \multirow{3}{*}{$\begin{array}{c}2.3 \\
\text { (grp3) }\end{array}$} \\
\hline 4 & 11.8 & \multirow{2}{*}{$\begin{array}{c}7.2 \\
(\operatorname{grp} 4)\end{array}$} & 5.5 & \multirow{2}{*}{$\begin{array}{c}3.8 \\
\text { (grp4) }\end{array}$} & 2.9 & \\
\hline 3 & 11.1 & & 5.2 & & 2.9 & \\
\hline
\end{tabular}

\section{Location of mouse button switch}

In order to maximize the mechanical advantage of the index finger, it is recommend that the knuckle ridge of the hand corresponded with the apex of the mouse, and the mouse button switch reside directly under the fingertip which corresponds to $95 \%$ of the index finger length. Natural size delineations in index finger length data yielded four age groups: adult males, adult females and 13 year olds; and children ages 10-12; 6-8; and 3-5. The recommended locations of the mouse button switches by age group are $6.7 \mathrm{~cm}, 5.7 \mathrm{~cm}, 4.9 \mathrm{~cm}$, and $4.1 \mathrm{~cm}$, respectively.

\subsection{Activation force}

As shown in Table 2, the process deriving and using finger mass yielded three additional activation force values, all below current recommended range of activation forces of $0.50-1.0 \mathrm{~N}$. These included the adult female at a recommended $0.4 \mathrm{~N}$ activation force, ages $10-12$ years at $0.3 \mathrm{~N}$, and ages $4-9$ years at $0.2 \mathrm{~N}$.

Table 2: Recommended activation forces (AF), based on mean finger mass

\begin{tabular}{|c|c|c|c|}
\hline Age (yrs) & $\begin{array}{c}\text { Finger } \\
\text { mass }(\mathrm{g})\end{array}$ & $\begin{array}{c}\text { Calculated } \\
\mathrm{AF}(\mathrm{N})\end{array}$ & $\begin{array}{c}\text { Recommended } \\
\mathrm{AF}(\mathrm{N})\end{array}$ \\
\hline Adult ${ }^{\lambda}$ & 30.1 & 0.59 & $0.6(\operatorname{grp} 1)$ \\
\hline Adult ㅇ & 20.0 & 0.39 & $0.4(\operatorname{grp} 2)$ \\
\hline 12 & 16.9 & 0.33 & \\
11 & 14.2 & 0.28 & 0.3 \\
10 & 13.8 & 0.27 & $(\operatorname{grp} 3)$ \\
\hline 9 & 11.5 & 0.22 & \\
8 & 10.9 & 0.21 & 0.2 \\
7 & 9.3 & 0.18 & $($ grp 4) \\
6 & 6.4 & 0.13 & \\
5 & 6.0 & 0.12 & \\
4 & 5.8 & 0.11 & \\
\hline
\end{tabular}




\section{Discussion}

Based on anthropometric principles, smaller mice would be recommended for younger age groups. Inevitably, the natural delineations among adult males, adult females and the child age groups do not all fall in exactly the same place across all of the different mouse characteristics. However, distinct and consistent trends are observed. Recommendations can be made and further research can be pursued based on these trends. In total, three to four mouse sizes would be recommended, including: the existing standard-sized mouse sized for adult males; a size for adult females, which would include children down to around 11 years of age; a mouse for roughly 6 to 10 year olds, and possibly a mouse for the smallest users who are less than six years old.

Coincidentally, trends in age group divisions for mice characteristics happen to correlate well with grades and schooling in the conventional United States education system. As seen in Table 3, natural divisions anthropometrically roughly divide age groups to be: adult male with same gender high school, adult female with same gender high school, junior high school, elementary school, and prior to elementary school.

Table 3: Summary of recommended device sizes and activation forces by age and grade level

\begin{tabular}{|c|c|c|c|}
\hline $\begin{array}{l}\text { Age } \\
\text { (yrs) }\end{array}$ & Grade & $\begin{array}{c}\text { Recommended } \\
\text { mouse dimensions } \\
\mathrm{L} \times \mathrm{W} \times \mathrm{H}(\mathrm{cm})\end{array}$ & $\begin{array}{l}\text { Recommended } \\
\text { Activation } \\
\text { Force }(\mathrm{N})\end{array}$ \\
\hline $\begin{array}{c}\text { Adult } \\
\hat{0}\end{array}$ & Adult $\hat{\sigma}$ & $12.0 \times 6.2 \times 3.8$ & 0.6 \\
\hline Adult & Adult $q$ & $12.0 \times 5.0 \times 3.8$ & 0.4 \\
\hline 13 & $9-10$ & $10.0 \times 5.0 \times 2.6$ & 0.3 \\
\hline 12 & $8-9$ & $10.0 \times 5.0 \times 2.6$ & 0.3 \\
\hline 11 & $7-8$ & $10.0 \times 5.0 \times 2.6$ & 0.3 \\
\hline 10 & $5-6$ & $10.0 \times 5.0 \times 2.6$ & 0.3 \\
\hline 9 & $4-5$ & $8.5 \times 4.4 \times 2.6$ & 0.2 \\
\hline 8 & $3-4$ & $8.5 \times 4.4 \times 2.6$ & 0.2 \\
\hline 7 & $2-3$ & $8.5 \times 4.4 \times 2.6$ & 0.2 \\
\hline 6 & $1-2$ & $8.5 \times 4.4 \times 2.6$ & 0.2 \\
\hline 5 & K-1 & $8.5 \times 4.4 \times 2.3$ & 0.2 \\
\hline 4 & Pre-K & $7.2 \times 3.8 \times 2.3$ & 0.2 \\
\hline 3 & Preschool & $7.2 \times 3.8 \times 2.3$ & 0.2 \\
\hline
\end{tabular}

These anthropometrically-driven recommendations represent a starting point from which further research may be needed, and should not be taken in isolation of additional cognitive and developmental considerations, including: understanding of the alphabet; the need for additional visual, tactile and potentially au- ditory feedback and stimuli; gross and fine motor skill development including hand-eye coordination; and potential differential vulnerability computerrelated vision disorders. These considerations are likely to affect the younger age groups (i.e. ages 4-8 years) in particular. More research and collaboration in the developmental sciences is needed to characterize the extent to which these factors influence effective computer use and comfort.

Additionally, with the introduction of virtual or soft computer devices such as on smart phones and tablets, the need for information on how gesturing, inputting or querying information on a virtual surface differs from the more traditional devices increases. Although scientific information especially as it relates to gender, age, and task characterization may be limited in this field, virtual devices have the additional potential for self-modifying user-specific sizing.

Moreover, the field would benefit from studies that empirically track and characterize how children use and interact with computers, and analyze typing proficiency from elementary, middle school, and high school computer classes in order to inform anthropometrically-driven recommendations for keyboard use as well. By characterizing tasks, teaming and time spent on computers, more opportunities will arise to teach this new generation of computer users proper ergonomic form, including when to take breaks and how to set up their workstation.

\section{Conclusion}

There is a need to determine whether United States and International standards for computer mouse size and activation force are appropriate for smaller statured computer users, including women and children. Objective anthropometric data can be utilized in redefining the computer input design process and can lend insight on creating new standards to promote effective ergonomics for this new generation of computer users.

\section{Acknowledgements}

A portion of this research was supported with a research grant from the Washington State Medical Aid and Accident Fund administered by the Department of Occupational Health Sciences at the University of Washington. Additional support was provided 
through of gift from the Ergonomic Research and Development Group within Hewlett-Packard.

\section{References}

[1] Baker, N. A., K. Jacobs, and J. Carifio. "The Ability of Background Factors, Work Practices, and Psychosocial Variables to Predict the Severity of Musculoskeletal Discomfort." Occupational Ergonomics. 2.1 (2000): 27-42.

[2] Blackstone, J. M., C. Karr, J. Camp, and P. W. Johnson. "Physical Exposure Differences between Children and Adults When Using Standard and Small Computer Input Devices." Ergonomics 51, no. 6 (2008): 872-89.

[3] Blatter, B. M., and P. M. Bongers. "Duration of Computer Use and Mouse Use in Relation to Musculoskeletal Disorders of Neck or Upper Limb." International Journal of Industrial Ergonomics 30, no. 4-5 (2002): 295-306.

[4] Breen, R., S. Pyper, Y. Rusk, and S. Dockrell. "An Investigation of Children's Posture and Discomfort During Computer Use." Ergonomics 50, no. 10 (2007): 1582-92.

[5] Chaffin DB, Andersson GBJ., and Martin, BJ (eds), 2006, Occupational Biomechanics (4th ed.) (New York: John Wiley).

[6] Cui L. "Performance and Physical Exposure Differences between Children and Adults When Using Standard and Small Computer Input Devices." University of Washington, 2009.

[7] DeBell, M, and C Chapman. "Computer and Internet Use by Students in 2003: Statistical Analysis Report." Washington, DC: National Center for Education Statistics, U.S. Department of Education., 2006.

[8] Dennerlein, JT, and PW Johnson. "Changes in Upper Extremity Biomechanics across Different Mouse Positions in a Computer Workstation." Ergonomics 49, no. 14 (2006): 1456-69.

[9] Harris C. and Straker L. "Survey of physical ergonomics issues associated with school childrens' use of laptop computers." International Journal of Industrial Ergonomics. Vol: 26 Issue: 3 (2000)
[10]Hwang S and PW Johnson. "Computer Input Devices - Race and Gender: Is there a mismatch between anthropometry and input device design." In: Proceedings of the Human Factors and Ergonomics Society 54th Annual Meeting (2010): 11301133.

[11]Jacobs, K, and NA Baker. "The Association between Children's Computer Use and Musculoskeletal Discomfort." Work 18, no. 3 (2002): 6.

[12]Johnson, P. W., and J. M. Blackstone. "Children and Gender Differences in Exposure and How Anthropometric Differences Can Be Incorporated into the Design of Computer Input Devices." Scandinavian Journal of Work Environment \& Health (2007): 26-32.

[13]Jones, C, and B Orr. "Computer-Related Musculoskeletal Pain and Discomfort among High School Students." American Journal of Health Studies 14, no. 1 (1998): 5.

[14]Pascarelli, E. F., and J. J. Kella. "Soft-Tissue Injuries Related to Use of the Computer Keyboard - a Clinical-Study of $53 \mathrm{Se}$ verely Injured Persons." Journal of Occupational and Environmental Medicine 35, no. 5 (1993): 522-32.

[15]Rathburn AH, West J, and Hausken EG. "Young Children's Access to Computers in the Home and at School in 1999 and 2000." Washington, DC: U.S. Department of Education, National Center for Education Statistics, 2003.

[16]Sommerich, C. M., R. Ward, K. Sikdar, J. Payne, and L. Herman. "A Survey of High School Students with Ubiquitous Access to Tablet Pcs." Ergonomics 50, no. 5 (2007): 706-27.

[17]Wahlstrom, J. "Ergonomics, Musculoskeletal Disorders and Computer Work." Occupational Medicine-Oxford 55, no. 3 (2005): 168-76.

[18]Wahlstrom, J., J. Svensson, M. Hagberg, and P. W. Johnson. "Differences between Work Methods and Gender in Computer Mouse Use." Scandinavian Journal of Work Environment \& Health 26, no. 5 (2000): 390-97.

[19]Westling G, Johansson RS. "Factors influencing the force control during precision grip“ Exp Brain Res. 1984;53(2):27784 